\title{
Preferências Ambientais e Possibilidades de Restauro Psicológico em Campi Universitários
}

\author{
Dayse da Silva Albuquerque \\ Universidade Federal de Santa Catarina, SC, Brasil. \\ Dnyelle Souza Silva \\ Universidade de São Paulo, SP, Brasil. \\ Ariane Kuhnen \\ Universidade Federal de Santa Catarina, SC, Brasil.
}

\begin{abstract}
Resumo: No cenário urbano, a distribuição da vegetação e seus aspectos de qualidade ambiental repercutem nos modos de vida das populações em termos de saúde e qualidade de vida. $\mathrm{O}$ investimento em espaços verdes, com ampla variedade de elementos naturais, pode promover a redução dos níveis de estresse e fadiga mental. Em ambientes universitários, por exemplo, os estudantes sentem-se constantemente fatigados devido às exigências para um bom desempenho. Considerando pesquisas na área de Psicologia Ambiental que têm constatado os benefícios para a saúde provenientes do contato com espaços verdes, esse estudo buscou identificar lugares escolhidos por estudantes para descanso em dois campi universitários brasileiros. Explorou ainda elementos de preferências e percepções ambientais associadas à capacidade restaurativa desses espaços. A entrevista, associada a uma variação da técnica de ambiente fotografado, possibilitou a análise das características desses espaços. As escolhas citadas pelos 50 alunos de cada campus direcionaram a discussão. Os discursos dos discentes revelaram possibilidades de restauro psicológico no ambiente universitário. Em ambos os campi, o contato com espaços verdes abertos pareceu estar associado a momentos de interação entre pessoas e o ambiente, de maneira mais ativa ou mais passiva. No campus 2 , as interações com os espaços verdes foram predominantemente ativas, apesar do campus 1 ter área de vegetação mais extensa. Dessa forma, compreende-se que a vivência restauradora se dá na relação pessoa-ambiente e é permeada por sutilezas que perpassam distintas realidades sociais. Palavras-chave: Psicologia Ambiental, Ambiente Universitário, Espaços Verdes, Preferências.
\end{abstract}




\title{
Environmental Preferences and Psychological Restoration possibilities in Universities Campuses
}

\begin{abstract}
In the urban context, the distribution of vegetation and its aspects of environmental quality have repercussions on the ways of life of the population in terms of health and quality of life. The investment in green spaces, with wide variety of natural elements, can promote the reduction of stress and mental fatigue levels. In academic environments, for example, students feel constantly fatigued due to requirements for good performance. Whereas research in the environmental psychology area have found the health benefits from the contact with green spaces, this study sought to identify resting places chosen by students in two Brazilian campuses. In addition, the research explored the preferences and environmental perceptions associated with the restorative capacity of these spaces. The interview, associated with a variation of the photographed environment technique, enabled the analysis of the characteristics of these spaces. The choices cited by 50 students from each campus guided the discussion. The speeches of the students revealed psychological restoration possibilities in the college environment. On both campuses, contact with open green spaces appear to be associated with moments of interaction between people and environment, in either a more passive or more active way. On campus 2, interactions with the green spaces were predominantly active, despite the fact that campus 1 has a more extensive green area. Thus, it is understood that the restorative experience takes place in the person-environment relationship and is permeated by subtleties that underlie different social realities.
\end{abstract}

Keywords: Environmental Psychology, University Environment, Green Spaces, Preferences.

\section{Preferencias ambientales y posibilidad de restauración psicológica en Campus Universitarios}

Resumen: En el entorno urbano, la distribución de la vegetación y sus aspectos de calidad ambiental tienen repercusiones en los modos de vida de la población en términos de salud y calidad de vida. La inversión en espacios verdes, con una amplia variedad de elementos naturales, puede promover la reducción del estrés y los niveles de fatiga mental. En los ambientes universitarios, por ejemplo, los estudiantes se sienten constantemente fatigados debido a los requisitos para un buen rendimiento. Considerando que investigaciones en el área de la psicología ambiental han encontrado los beneficios para la salud del contacto con espacios verdes, este estudio trata de identificar los lugares elegidos por los estudiantes para descansar en dos campus universitarios brasileños. Se exploraron las preferencias y percepciones ambientales asociadas con la capacidad reparadora de los espacios verdes. La entrevista, asociada con una variación de la técnica de ambiente fotografiado, permitió el análisis de las características de estos espacios. Las opciones citadas por 50 estudiantes de cada campus guían la discusión. Los discursos de los estudiantes revelaron posibilidad de restauración psicológica en el ámbito universitario. En los dos campus, el contacto con los espacios verdes abiertos parece estar asociado con momentos de interacción entre las personas y el ambiente, de manera más pasiva o más activa. En el campus 2, las interacciones con los espacios verdes fueron mayormente activas, aunque el campus 1 tiene más extensa zona verde. Por lo tanto, se entiende que la experiencia de restauración se lleva a cabo en la relación persona-ambiente y está impregnada de sutilezas que subyacen a las diferentes realidades sociales.

Palabras clave: Psicología Ambiental, Ambiente Universitario, Espacios Verdes, Preferencias. 


\section{Introdução}

No cenário urbano, a distribuição da vegetação e seus aspectos de qualidade ambiental repercutem nos modos de vida das populações, em especial no que diz respeito à saúde e qualidade de vida. O investimento em espaços verdes, com ampla variedade de elementos naturais, pode promover a redução dos níveis de estresse e fadiga mental, estimular a realização de atividades físicas, permitir e facilitar as interações sociais e auxiliar na prevenção de doenças, além de contribuir para ações comunitárias relacionadas ao cuidado ambiental (Comstock et al., 2010; Costa, \& Colesanti, 2011; Honold, Beyer, Lakes, \& Meer, 2012; Hur, Nasar, \& Chun, 2010).

Nesse artigo adotamos a concepção de espaços verdes que faz referência às áreas em que a vegetação é predominante, seja gramínea e/ou arbórea, e com as quais é possível interagir de maneira passiva ou ativa (Barcellos, 1999; Castelnou, 2006). As interações ativas envolvem ações que possibilitam maior proximidade com os espaços verdes, principalmente através do uso do tato. $\mathrm{E}$ as interações passivas referem-se à observação e contemplação dos elementos naturais presentes nos espaços verdes (McFarland, Waliczek, \& Zajicek, 2010). Esses espaços verdes podem estar inseridos em contextos predominantemente urbanos e, de acordo com suas características, podem exercer funções promotoras de benefícios psicológicos e sociais (Steuer, Araújo, Oliveira, Silva, \& El-Deir, 2012). Dentre os principais espaços verdes urbanos encontram-se as praças, parques e jardins.

Entre as áreas que se propõem a discutir os benefícios do contato humano com os espaços verdes, a Psicologia Ambiental tem buscado articular propostas de pesquisa que permitam tecer aproximações das inter-relações pessoa-ambiente, com o propósito de construir práticas pautadas em uma perspectiva que considera a influência mútua entre esses elementos (Polli, \& Kuhnen, 2011). O desafio é articular aspectos teóricos às metodologias de pesquisas que abarquem a complexidade dos fenômenos nos mais variados contextos, sem tornar o ambiente apenas cenário ou a pessoa apenas observador, implicando na necessidade de reconhecer o caráter ativo de ambos na construção da realidade.

Dentre os processos que têm sido explorados para discussão da relação pessoa-ambiente estão a percepção e a preferência ambiental. A percepção ambiental explora a dimensão cognitiva relacionada ao reconhecimento, organização e compreensão do ambiente a partir de imagens mentais e da experiência imediata. Associa-se a aspectos objetivos e subjetivos do ambiente, reconhecendo sua complexidade, o caráter ativo do indivíduo e do ambiente no processo e as demandas e vivências implicadas (Galindo, Gilmartín, \& Corraliza, 2002; García-Mira, 1997; Kuhnen, \& Higuchi, 2011).

As preferências ambientais perpassam o processo perceptivo (dimensão cognitiva), incorporando as dimensões afetiva e valorativa no estudo da relação pessoa-ambiente. A partir de características ligadas à estética da paisagem e da possibilidade de satisfação de necessidades, são reconhecidos elementos que suscitam sensações de agrado ou desagrado. Esse processo desencadeia a atração ou repulsa por determinados lugares de acordo com critérios perceptivos bastante sutis (Berg, Koole, \& Wulp, 2003; Korpela, \& Hartig, 1996). Baseados nesses processos, estudos têm apresentado resultados associados ao bem-estar físico e emocional das pessoas no contato com a natureza, proveniente do alto valor estético percebido em ambientes naturais (Galindo et al., 2002).

Os estudos sobre preferência ambiental têm sido direcionados por distintas abordagens de avaliação da qualidade estética do ambiente, destacando-se as perspectivas de Appleton, Ulrich e Kaplan. Os resultados de pesquisas nesse campo estão associados à capacidade restaurativa do ambiente e à redução do estresse (Beute, \& Kort, 2013).

Em meados das décadas de 1970 e 1980, JayAppleton e Roger Ulrich publicaram pesquisas estabelecendo relações entre percepções visuais/estéticas dos ambientes e respostas emocionais. Ambos deram ênfase, com base em uma abordagem psicoevolucionista, a determinadas características que promovem respostas psicofisiológicas associadas ao instinto humano de sobrevivência. Para eles, a necessidade de posicionamento e ação do indivíduo perante um ambiente que suscite reações específicas pode tanto desencadear estresse quanto promover o alívio de tensões (Gatersleben, \& Andrews, 2013; Gressler, \& Günther, 2013).

Além da teoria de recuperação do estresse proposta por Ulrich (1983) e Ulrich et al. (1991) para explicar as sensações de prazer e desprazer resultantes da avaliação do ambiente, surgiu, na década de 1980, a teoria de restauração da atenção, na qual Rachel e Stephen Kaplan (Kaplan, \& Kaplan, 1989) preconizam 
que os indivíduos tendem a buscar ambientes que reduzam a necessidade de atenção focada e proporcionem relaxamento. $\mathrm{O}$ estresse foi o protagonista nessas teorias, entendido como uma resposta psicofisiológica às demandas do cotidiano com as quais o indivíduo não consegue lidar de maneira saudável (Evans, \& Cohen, 1987). A abordagem do termo restauração (restoration) segue a orientação de um processo de recuperação de aspectos físicos, psicológicos ou da capacidade social, não alcançados devido ao esforço contínuo e repetitivo para a interpretação de estímulos (Hartig, \& Staats, 2003).

Baseados no conceito de atenção voluntária de William James, Kaplan e Kaplan (1982, 1989) e Kaplan (1995), defendem a existência de ambientes restauradores que apresentam fatores específicos (escape, extensão, fascinação e compatibilidade) atrelados ao bem-estar daqueles que se relacionam com tais ambientes. O escape envolve a sensação de fuga propiciada pelo afastamento físico e mental de lugares considerados estressantes. A extensão alude ao nível de acessibilidade do ambiente e ao elo afetivo com o lugar através da pertença. A fascinação refere-se ao uso da atenção involuntária que permite ao organismo o descanso necessário para se recuperar. A compatibilidade está associada à capacidade do ambiente de satisfazer as necessidades de uso do indivíduo que o acessa (Alves, 2011; Herzog, Maguire, \& Nebel, 2003; Kaplan, \& Kaplan, 2011). Porém, o reconhecimento desses fatores depende da inter-relação pessoa-ambiente.

Estudos nessa área afirmam que há uma tendência de ambientes naturais serem percebidos como potencialmente mais restauradores que ambientes construídos. Essa preferência por espaços verdes em contexto urbano tem prevalecido em pesquisas que buscam entender estas diferenças (Kaplan, 1995; Berg, Hartig, \& Staats, 2007). Entretanto, tem-se questionado a simplificação e tendenciosidade da teoria nesse sentido, ao descontextualizar aspectos sociais e históricos nesses processos mediadores da relação pessoa-ambiente (Gressler, \& Günther, 2013; Staats, \& Hartig, 2004). Para conceber aproximações a respeito das preferências ambientais e os benefícios do contato com espaços verdes em cenário urbano faz-se necessário construir questionamentos voltados para as escolhas das pessoas em relação a determinados ambientes e suas características, além das motivações atreladas ao uso desses espaços. Devem-se considerar as especificidades de cada contexto e as relações que são estabelecidas de um ponto de vista macro e microcultural.

Comumente o uso de espaços verdes está associado a lugares públicos, os quais são frequentados esporadicamente por indivíduos que buscam intencionalmente fugir da rotina. Contudo, os espaços verdes também podem estar presentes em contextos de vivência diária, como escolas, universidades, hospitais e empresas (Andrade, Lima, Fornara \& Bonaiuto, 2012; Felsten, 2009; Raanaas, Horgen, Rich, Sjøstrøm, \& Patil, 2011). Durante o processo de desenvolvimento, as pessoas vinculam-se a esses ambientes institucionais, de uso comum e compartilhado por distintos grupos sociais, de maneira que a qualidade de vida das pessoas está atrelada à salubridade desses locais (Fischer, s/d; Gilmartín, 2002). Diferentes grupos, em momentos distintos do desenvolvimento humano, percebem e vivenciam ambientes resguardando especificidades no que concerne a preferências e possibilidades de restauro (Berg, Vlek, \& Coeterier, 1998; Scopelliti, \& Giuliani, 2004).

As demandas cotidianas de ambientes institucionais resultam cada vez mais em níveis elevados de estresse e insatisfação. Em sua tese, Gressler (2014) concebeu um paralelo entre lugares escolhidos para descanso e os fatores que caracterizam os ambientes restauradores, o que permitiu relacionar aspectos subjetivos aos requisitos para restauração entre operários. Em ambientes universitários, por exemplo, os estudantes sentem-se constantemente fatigados devido às exigências para um bom desempenho acadêmico (Felsten, 2009; Kuhnen, 2012). Pesquisas realizadas em campi universitários constataram a importância de espaços verdes no entorno do campus (Lázaro, \& Cabrerizo, 2002) e a relação da presença desses espaços para o descanso (Felsten, 2009; Varney et al., 2014) e percepção de qualidade de vida dos discentes (McFarland, Waliczek, \& Zajicek, 2008; 2010; Speake, Edmonson, \& Nawaz, 2013).

Considerando a importância desses ambientes na rotina das pessoas e os benefícios dos espaços verdes para a saúde, este artigo pretende discutir os resultados de uma pesquisa que buscou identificar lugares escolhidos por estudantes para descanso em dois campi universitários e, a partir disso, explorar elementos de preferências ambientais e percepções associadas à capacidade restaurativa desses espaços. A proposta pauta-se na tentativa de subsidiar melhorias em processos de gestão universitária. 


\section{Método}

De caráter descritivo e exploratório, o estudo seguiu viés qualitativo e teve como objetivo identificar as preferências ambientais de estudantes de graduação em relação aos lugares de descanso em dois campi universitários. Buscou-se evidenciar características associadas à capacidade restaurativa do ambiente, de maneira a compreender aspectos perceptuais sobre os espaços verdes e as interações dos estudantes com esses locais.

Foram realizadas entrevistas com roteiro semiestruturado articuladas a uma variação da técnica do ambiente fotografado. Essa técnica consiste na seleção de imagens representativas do tema de estudo com o intuito de apreender as principais percepções sobre o ambiente em foco (Higuchi, \& Kuhnen, 2008). A variação da técnica empregada nesse estudo partiu do discurso dos estudantes para a análise das paisagens fotografadas. Os locais de cada campus foram selecionados de acordo com as citações dos estudantes nas entrevistas e foram posteriormente fotografados pelas pesquisadoras. As imagens, além de ilustrar os espaços de cada campi, subsidiaram a avaliação de características relacionadas às preferências ambientais, de acordo com a literatura, e as falas dos estudantes guiaram a exploração de percepções ligadas à capacidade restaurativa desses ambientes.

As entrevistas ocorreram em dois campi universitários localizados respectivamente nas regiões Norte e Sul do Brasil. A escolha dos campi se deu por conveniência, disponibilidade e acesso das pesquisadoras.

O campus 1 , com $35 \%$ de área construída em seus 6,7 milhões de metros quadrados, abriga o maior fragmento florestal em área urbana do país. Em 2012, foi instituído como Área de Proteção Ambiental (APA) através do Decreto no 1503/2012. Essa área reúne 759,15 hectares, incorporando, além do campus universitário, um instituto de pesquisa, um parque e um conjunto residencial, todos envoltos por espaços verdes. O campus 2 , dispõe de ampla estrutura, incluindo biblioteca, restaurantes, hospital, centro de convivência e eventos, gráfica, escolas de ensino fundamental e infantil, além de um bosque de ampla área verde, no qual se encontra um córrego e um planetário. Dos um milhão de área total do campus, suas construções correspondem a aproximadamente 275 mil metros quadrados.

\section{Participantes}

Participaram 100 pessoas $(\mathrm{M}=48 ; \mathrm{F}=52) \mathrm{e}$ buscou-se a aproximação equivalente quanto ao sexo. Assim, foram entrevistados 26 mulheres e 24 homens em cada instituição, com idade entre 18 e 55 anos, sendo 50 estudantes de cada campus, a partir do $2^{\circ}$ ano da graduação. A participação foi voluntária, conforme a disponibilidade apresentada por cada um ao ser convidado para a entrevista no espaço da instituição e assinatura em Termo de Consentimento Livre e Esclarecido.

\section{Procedimentos éticos}

Os parâmetros éticos dispostos na Resolução $\mathrm{n}^{\circ}$ 466/2012 do Conselho Nacional de Saúde foram considerados em todo o processo de elaboração e execução desse estudo. Dessa forma, a coleta de dados se deu somente após a aprovação no Comitê de Ética em Pesquisa com Seres Humanos sob parecer $\mathrm{n}^{\circ} 1.044 .668$.

\section{Procedimentos de coleta e análise de dados}

Os estudantes foram entrevistados a partir de um roteiro de perguntas abertas em relação às preferências e usos de espaços para descanso no campus. As entrevistas tiveram duração média de 20 minutos e ocorreram nos períodos da manhã e tarde, em diferentes dias da semana e em distintos locais de cada campus, de maneira a acessar alunos das áreas de humanas (47\%), exatas (25\%), biológicas (17\%) e agrárias (11\%), e dos turnos integral (44\%), noturno (17\%), matutino (14\%), vespertino (14\%) e diurno (11\%).

O conteúdo das entrevistas foi audiogravado e posteriormente transcrito em planilha para análise. Para análise dos dados foi necessária a transcrição integral das entrevistas, contudo, considerou-se para a discussão somente os aspectos concernentes aos lugares escolhidos para descanso e às justificativas advindas dessas escolhas ${ }^{1}$. Após a organização dos dados coletados, foi possível identificar os lugares citados pelos estudantes em cada campus, sendo as informações complementadas com a variação da técnica de ambiente fotografado.

\footnotetext{
${ }^{1}$ A questão norteadora para os resultados e discussão dessa pesquisa refere-se a: "Quando você está cansado e quer se distanciar da rotina de aulas há algum lugar dentro do campus que você costuma buscar para se distrair, relaxar, refletir? Onde fica esse espaço e porque você escolheu esse lugar?".
} 
As pesquisadoras percorreram cada campus fotografando os locais citados nas entrevistas e observando o uso dos estudantes em relação a esses espaços. As fotografias foram realizadas em diferentes ângulos e posteriormente foram selecionadas aquelas que apresentaram melhor qualidade de imagem para ilustrar os discursos dos estudantes e permitir a discussão sobre elementos de preferência ambiental presentes na literatura.

\section{Resultados e discussão}

Os resultados serão apresentados em duas seções: a primeira corresponde aos dados do campus 1 (região norte) e a segunda relativa aos dados do campus 2 (região sul). Dessa forma, as características dos locais escolhidos pelos estudantes serão evidenciadas de acordo com as especificidades de cada instituição de ensino e sua localização regional.

\section{Campus 1}

Dentre os 54 locais citados pelos estudantes como promotores de descanso, surgiram tanto ambientes construídos quanto espaços verdes com diferentes níveis de interação. O espaço verde mais citado pelos entrevistados para um momento de distanciamento da rotina acadêmica foi a área de vegetação gramínea e arbórea localizada no entorno da Faculdade de Educação Física (Figura 1). Essa área engloba o gramado ao redor das quadras de esporte, piscina e campo de futebol. Ainda nesse ambiente, destacam-se as trilhas de caminhada utilizadas principalmente por alunos dos cursos de ciências agrárias e biológicas para aulas práticas. Também foi possível observar discentes usando as trilhas para prática de atividade física, por meio de caminhada e corrida (Figura 2), evidenciando interações ativas e grupais nesses locais. Foram escolhidos espaços verdes localizados atrás dos blocos de sala de aula por aqueles que buscavam maior isolamento (Figura 3) e interações passivas.

A preferência por espaços que apresentam elementos naturais vem sendo discutida por perspectivas evolucionistas desde a década de 1970 (Appleton, 1975; Ulrich, 1977). Sob essa perspectiva, Kaplan e Kaplan (1982) e Ulrich (1979) teceram modelos de preferência estética da paisagem pautados em análises interpretativas de informações fornecidas por distintas configurações do ambiente físico. Tais modelos defendem que a escolha por determinados lugares está atrelada a propriedades específicas, que permitem uma visualização ampla do espaço que está sendo acessado, além de uma noção que remete ao mistério e à possibilidade de exploração contínua, ou seja, a paisagem não se esgota em um único relance, mas permite que o indivíduo perceba novas facetas à medida que frequenta e torna esse ambiente mais familiar (Balling, \& Falk, 2005).

No caso do espaço verde mais citado pelos estudantes no campus 1 , foi possível destacar, dentre os padrões estabelecidos por Kaplan, Kaplan e Ryan (1998), o amplo acesso visual percebido na área $\mathrm{e}$ a própria textura da superfície do solo coberto por grama, que fortalecem as sensações de conforto e agradabilidade. Esse tipo de espaço apresenta uma coerência e organização que dialogam com a necessidade de indivíduos que buscam reduzir o uso da atenção voluntária no dia a dia (Berg et al., 2003).

As trilhas podem ser percebidas a partir de aspectos que remetem tanto ao agrado quanto ao desagrado. São compatíveis com a necessidade de exploração, por apresentarem níveis de mistério e profundidade que aumentam a complexidade do ambiente. Esses aspectos são considerados favoráveis para proximidade humana. Contudo, por situarem-se em áreas de vegetação densa que reduzem a visibilidade e facilitam o refúgio de animais silvestres e pessoas, podem gerar sentimentos de medo e inse-

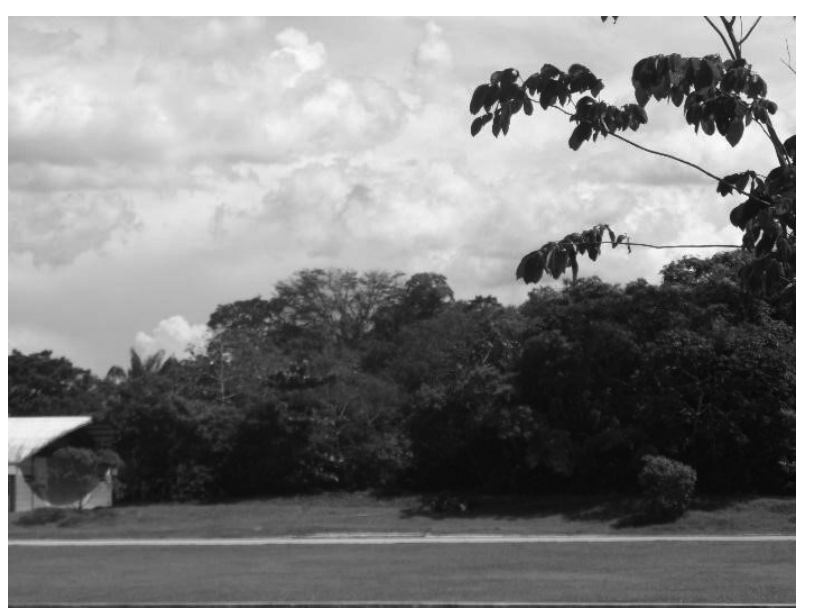

Figura 1

Área do entorno da Faculdade de Educação Física com extensa vegetação gramínea, arborização e sombreamento. 
gurança (Gatersleben, \& Andrews, 2013). Os espaços verdes localizados aos finais dos blocos de sala de aula permitem um maior distanciamento físico e psicológico do cotidiano acadêmico. Esse escape é potencializado pela contemplação da paisagem e pela possibilidade de ouvir o som dos pássaros, por exemplo, conforme Kaplan e Kaplan (2011).

Entre os motivos trazidos pelos alunos para escolha desses espaços, destacam-se conteúdos relacionados à capacidade restaurativa do ambiente e ao conforto térmico. Martínez-Soto e López-Lena (2010) referem que a preferência ambiental é mediada pela percepção de qualidades restauradoras que direcionam a relação pessoa-ambiente. No campus universitário são constantes as demandas por atenção e concentração, o que induz à necessidade de momentos de pausa para recuperação da fadiga mental (Felsten, 2009). A busca por locais que permitam descanso e relaxamento dentro do próprio campus expande a concepção de universidade como instituição para fins unicamente acadêmicos. Ela pode ser também lugar de encontros, trocas, lazer, descanso, desenvolvimento pessoal e profissional, assim como oportunizar melhor desempenho acadêmico devido à oportunidade de recuperação da atenção que o ambiente oferece.
A possibilidade de restauro é evidenciada, por exemplo, na fala: "é mais isolado assim das pessoas, aí dá, [para] extravasar esse estresse" (M, 22 anos), que enfatiza o fator escape, característico dos ambientes restauradores. Esses espaços ganham destaque ainda por permitirem contato com a natureza e possibilitarem contemplação de uma paisagem esteticamente agradável, como: "um campo aberto [...] e aí geralmente no fim da tarde, dá pra ver bem o pôr do sol" (F, 22 anos).

Por ser uma área localizada no entorno da Faculdade de Educação Física, os estudantes utilizam os espaços como ponto de encontro com os amigos, conforme comenta: "permite que a gente aprecie a vista e é um espaço bom e agradável pra gente conversar e ficar com os amigos" (F, 22 anos) e para a prática de exercícios: "eu gosto de jogar bola lá, a gente sempre joga, se distancia, esquece das coisas, menos preocupações" (M, 20 anos). Nesse sentido, esses espaços verdes demonstram compatibilidade com as necessidades dos discentes ao propiciarem a realização de atividades que auxiliam no processo de restauro psicológico e demonstram o aspecto funcional dessas relações.

Os últimos corredores dos blocos (Figura 4) e os corredores localizados no segundo andar dos prédios (Figura 5) apresentam funções variadas, pois apresentam configurações que dificultam um
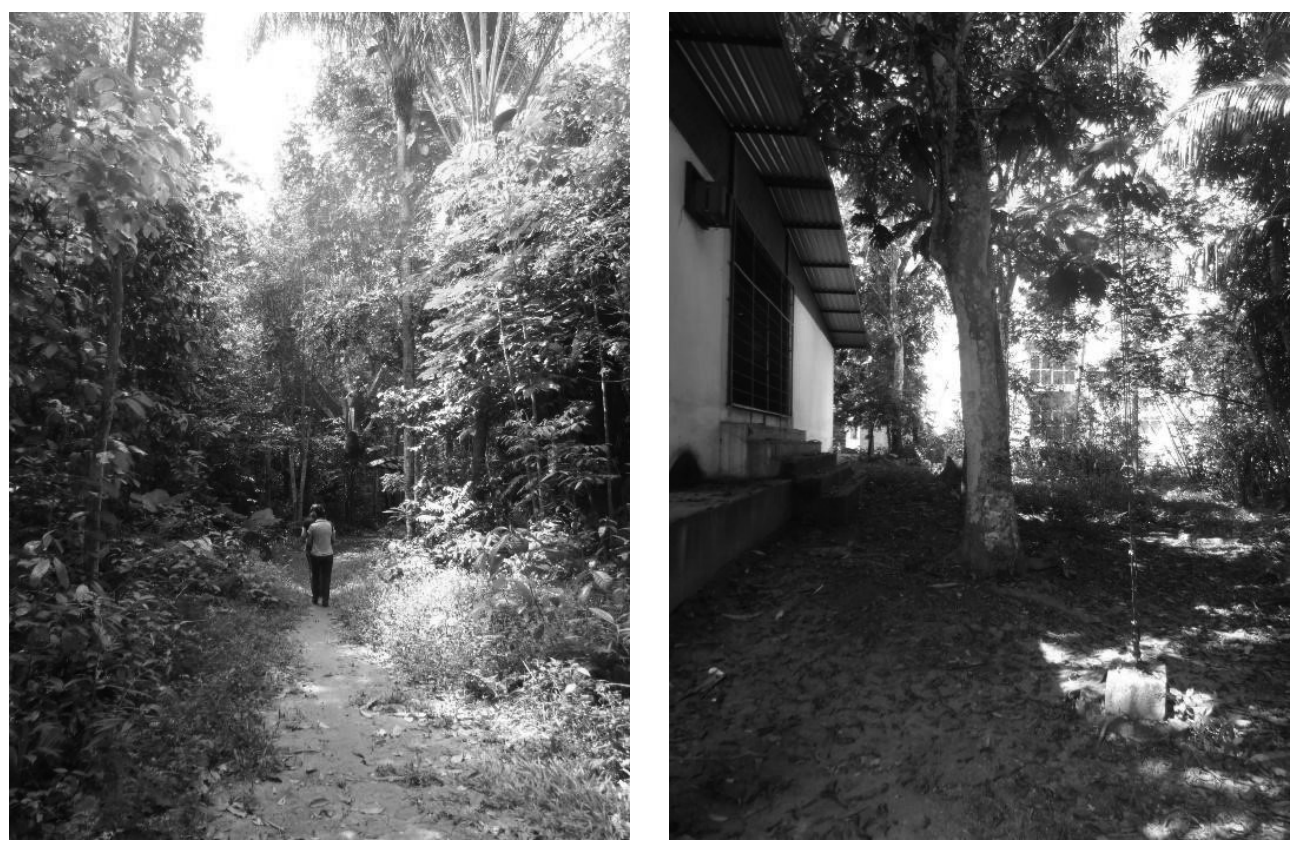

Figuras 2 e 3

A figura à esquerda ilustra as trilhas de caminhada localizadas na área da Faculdade de Educação Física, utilizadas principalmente para aulas práticas e a figura à direita representa o final de um dos blocos de aula. 
distanciamento pleno das atividades acadêmicas. São utilizados de acordo com as demandas estudantis e permitem interações passivas com elementos naturais do entorno do campus, conforme as falas: "o movimento é bem fraco, [...] é um lugar de silêncio, né, é pra estudo, às vezes também eu fico estudando lá..." (M, 20 anos); "ali no final das salas que já tem a beirada pra mata, lá é bem calmo, bem tranquilo [...] ah, eu prefiro ficar sentada ali no final do corredor mesmo, perto do barulho dos passarinhos" (F, 28 anos).

Outros lugares, considerados como ambientes construídos, citados com menor frequência foram os laboratórios frequentados por cursos das áreas de exatas, salas de aula vazias, lanchonetes, escadas e hall de entrada, os quais apresentam um espaço amplo, aberto, com presença de bancos.

\section{Campus 2}

As preferências dos estudantes do campus 2 totalizaram a citação de 52 locais, predominando as interações ativas em espaços verdes. O lugar mais citado dentre os espaços verdes foi o Bosque (Figura 6) que circunda o Centro de Filosofia e Ciências Humanas. O Bosque é cortado por um córrego, um planetário, uma base de escoteiros e um parque (Kuhnen, 2012). Essa área de extensa vegetação gramínea é bastante arborizada, porém há poucos lugares com vegetação densa. Por ser amplo, alguns alunos citaram localizações específicas procuradas para maior isolamento como o palco do Bosque e as árvores de maior porte localizadas nas regiões mais periféricas.

A escolha do Bosque no campus 2 ratifica a preferência por ambientes com amplo acesso visual e superfície do solo com textura proveniente de vegetação gramínea. A busca por conforto térmico sofre variações de acordo com as estações, considerando-se que nesta região geográfica do país (Sul) há mudanças mais evidentes de temperatura e acesso ao sol. Dessa forma, é possível observar os discentes em áreas sombreadas durante o verão e em áreas ensolaradas no decorrer do inverno. Padrões de preferência ambiental relacionados à profundidade, mistério e complexidade (Kaplan et al., 1998) também estão presentes, o que o torna um lugar bastante frequentado pela comunidade interna e externa à instituição.

Além do Bosque, os estudantes demonstraram preferência por áreas de gramado localizadas em pontos distintos do campus, como a área no entorno do lago (Figura 7) ou ao redor do Templo Ecumênico
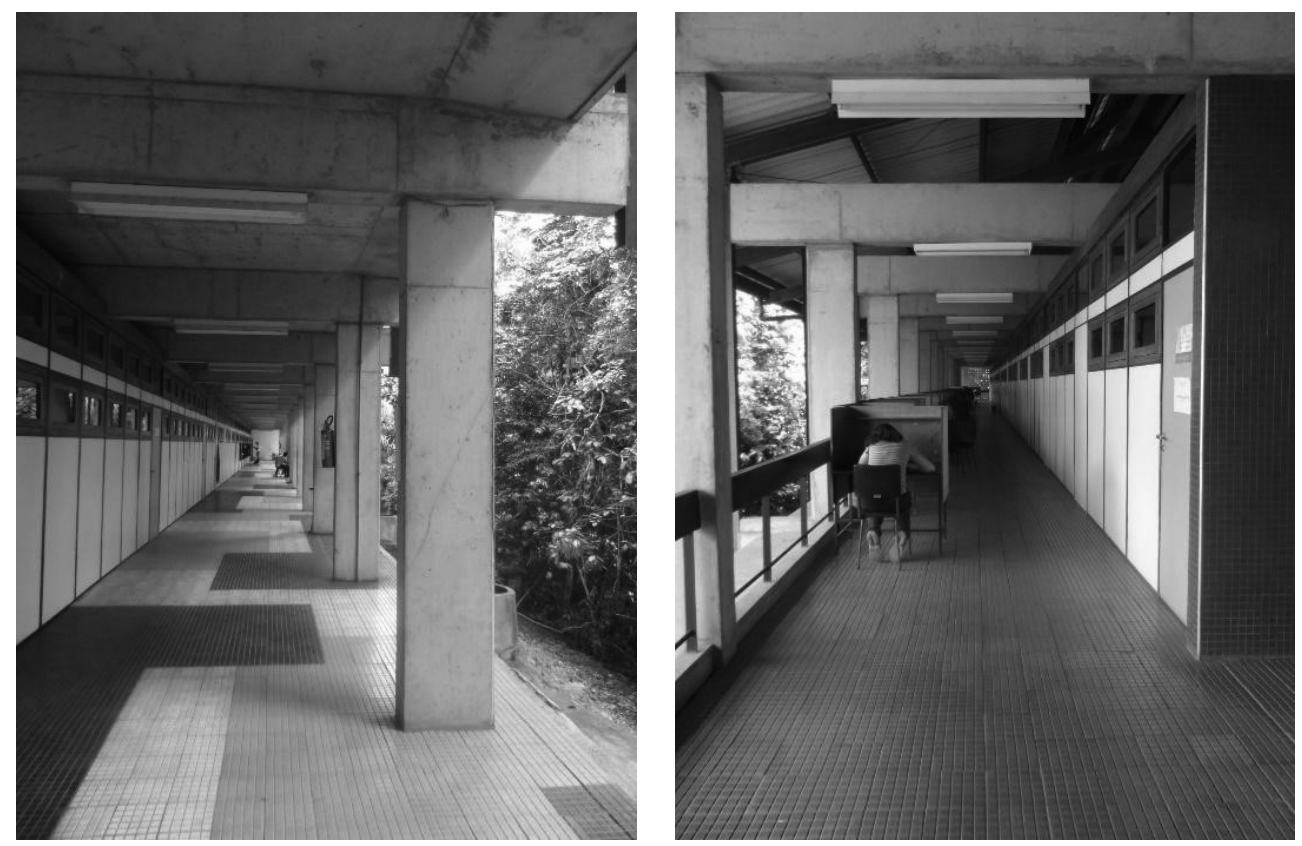

Figuras 4 e 5

A figura à direita apresenta o último corredor do campus por detrás da biblioteca e a figura à esquerda ilustra o corredor superior da biblioteca na qual se localizam cabines para estudo individual. Ambos os corredores propiciam também a visualização de espaços verdes com arborização densa. 
(Figura 8). A aproximação com a natureza nesses locais permite o fascínio e uma interação ativa com os elementos da paisagem. A estética paisagística de ambos os cenários evidencia a influência humana em sua formatação, o que, segundo Kaplan e Kaplan (1982), favorece a aproximação das pessoas pelo cuidado e manutenção observados.

A busca por esses espaços está associada às sensações de agradabilidade e calma percebidas, além do silêncio e da possibilidade de relaxamento. Para os discentes, a presença de locais assim, pode propiciar inúmeros benefícios, como ilustra a fala: "passam essa coisa do, da, da paz, da unidade, do ser natural com a natureza, essa coisa da troca de energia, dessa sensação de bem-estar, de fortalecimento..." (M, 42 anos), o que contribui para a valorização do campus e de seus espaços verdes. O conteúdo da fala destaca o sentimento de pertencimento e apropriação do lugar que surgem em discussões sobre ambientes restauradores ligadas ao fator extensão ou escopo.

O entorno do lago foi referido como um local que transmite paz, principalmente pelo contato com os animais: "é mais tranquilo, parece que o pessoal vai mesmo pra lá pra relaxar [...] fico ali olhando a movimentação dos animais" (F, 22 anos). Em relação ao entorno do Templo Ecumênico, Biblioteca e Reitoria, foi possível observar a presença de um fator agregador para a utilização destes espaços, que são mais intensamente ocupados às quartas-feiras, quando ocorre uma feira de produtos variados. Nesses dias, os alunos utilizam os espaços verdes para a prática de atividades físicas, piqueniques e para apreciação dos produtos oferecidos na feira, conforme demonstra a seguinte fala:

perto da reitoria, onde tem a feirinha, ali naquele centro onde tem as árvores, ali é um lugar que eu gosto bastante [...] eu acho mais tranquilo, eu acho mais afastado dos espaços de aula [...] é mais tranquilo assim e pela questão da feirinha mesmo, quando tem é o dia que eu mais tô ali, na quarta feira é onde mais as pessoas ficam (F, 21 anos).

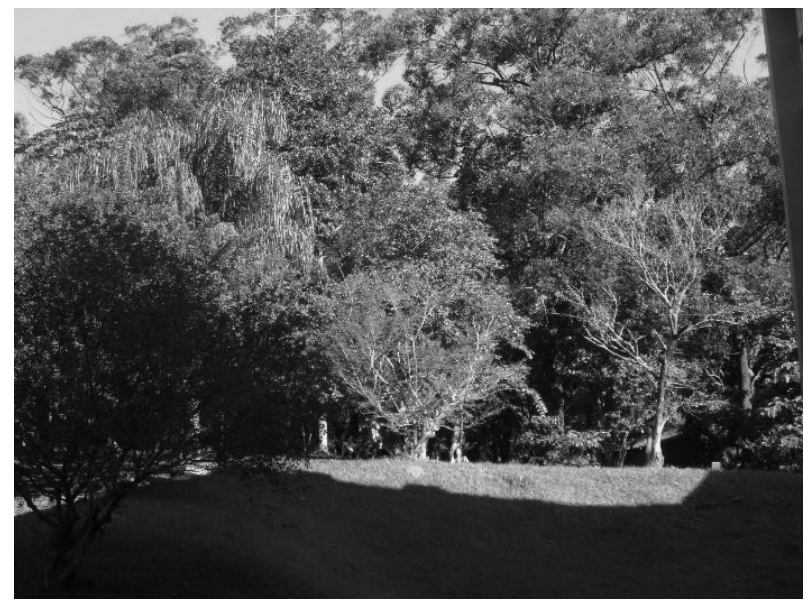

Figura 6

Área do Bosque localizada no entorno do Centro de Filosofia e Ciência Humanas, com extensa vegetação gramínea, arborização pouco densa e sombreamento.
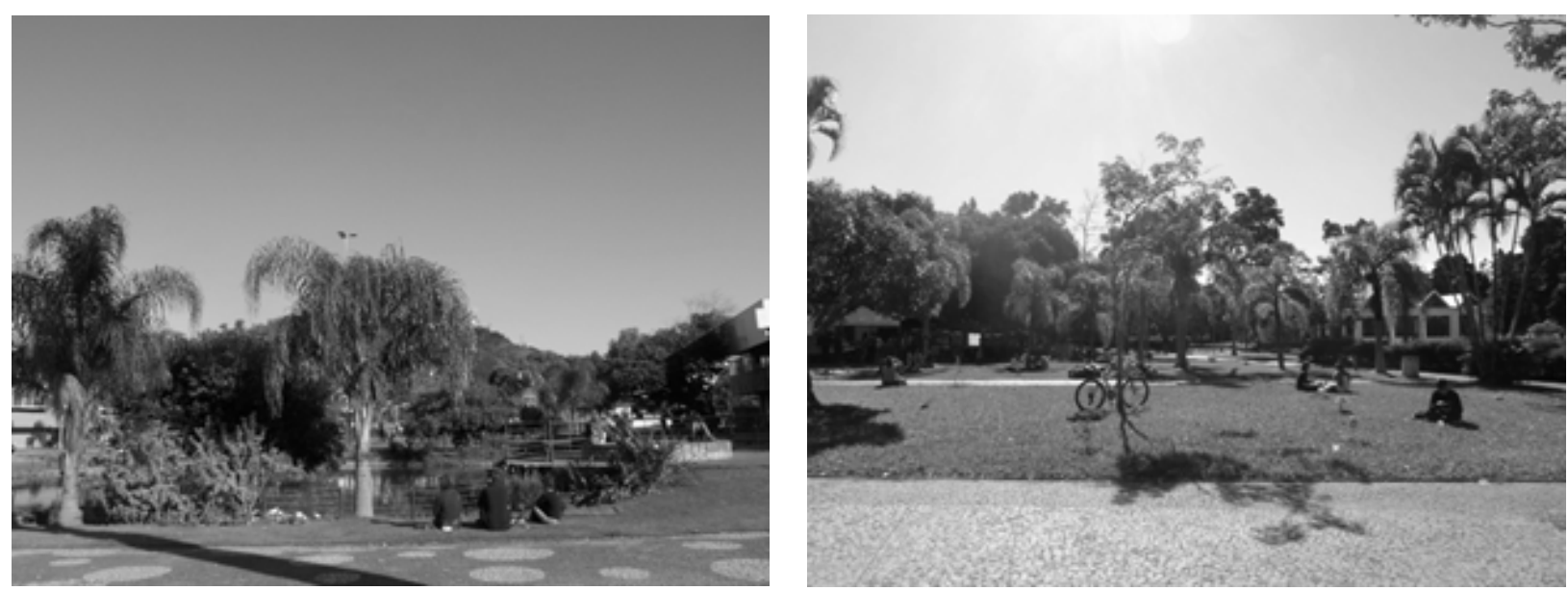

Figuras 7 e 8

A figura à esquerda corresponde à área de gramado no entorno do lago com a presença de animais (patos, gansos), arborização pouco densa e bancos e a figura à direita ilustra a área de gramado ao redor do Templo Ecumênico. 
Nesse sentido, a configuração desses espaços e as intencionalidades dos sujeitos que deles fazem uso estão claramente definidas. Há ainda a construção de territorialidades, ou seja, os alunos sentem-se mais confortáveis em fazer uso dos espaços verdes localizados no entorno dos prédios em que realizam suas atividades acadêmicas. A distribuição dos espaços verdes no campus surge como facilitador, mas há o reconhecimento de que essa distribuição é desigual e algumas áreas carecem de espaços de convivência com características naturais.

Quanto aos ambientes construídos, as escolhas dos estudantes foram mais distribuídas, tendo como local mais recorrente a biblioteca central, incluindo sua área interna e o corredor de acesso. A escolha da biblioteca foi atribuída às inúmeras possibilidades de atividades a serem realizadas nesse ambiente: "lá é calmo, posso sentar, posso ficar lá, posso ler um livro, posso mexer na internet, por mais que tenha livros e tenha referência de estudos, mas a gente busca outras coisas que, que, pra ocupar a mente assim..." (F, 19 anos). Além disso, a área da biblioteca onde ficam os puffs (Figura 9) foi mencionada como um local para descanso, facilitado pelo silêncio do local e clima agradável, o que se evidencia na fala: "lá [na biblioteca] é fresco, tem ar-condicionado [...] lá é sossegado, não tem barulho [...] e tem um puff que éo mais legal deitar, as cadeiras são muito ruins aqui pra descansar" (M, 19 anos).
Associado ao espaço da biblioteca destaca-se o seu corredor de acesso (Figura 10), que pode ser considerado um local de características mistas, principalmente pela presença dos bancos e corredor construído, que sugere pausa e contemplação da paisagem ao redor: "a maneira como fizeram, um corredor assim, aí os bancos pro pessoal já sentar, aí tu vê que tem até no gramado assim, interessante" (M, 22 anos). É possível notar que o espaço da biblioteca se apresenta de maneira ambígua, por possibilitar a realização de atividades distintas em consonância com as demandas de cada indivíduo. Além disso, sua área externa é percebida como convidativa principalmente pela composição paisagística, o que reitera a ideia de que a intervenção humana pode tornar os ambientes mais saudáveis. Isso ocorre à medida que a coerência e a organização dos ambientes são planejados de acordo com o contexto em que se encontram.

Dentre os demais ambientes construídos surgiram alguns centros acadêmicos, lanchonetes, salas de aula vazias e pátios dos prédios.

\section{Considerações finais}

Os resultados apresentados nesse artigo permitiram inferir algumas conclusões a respeito das preferências ambientais de acadêmicos de dois campi universitários brasileiros, assim como a capacidade restauradora desses ambientes. Entretanto, é impor-
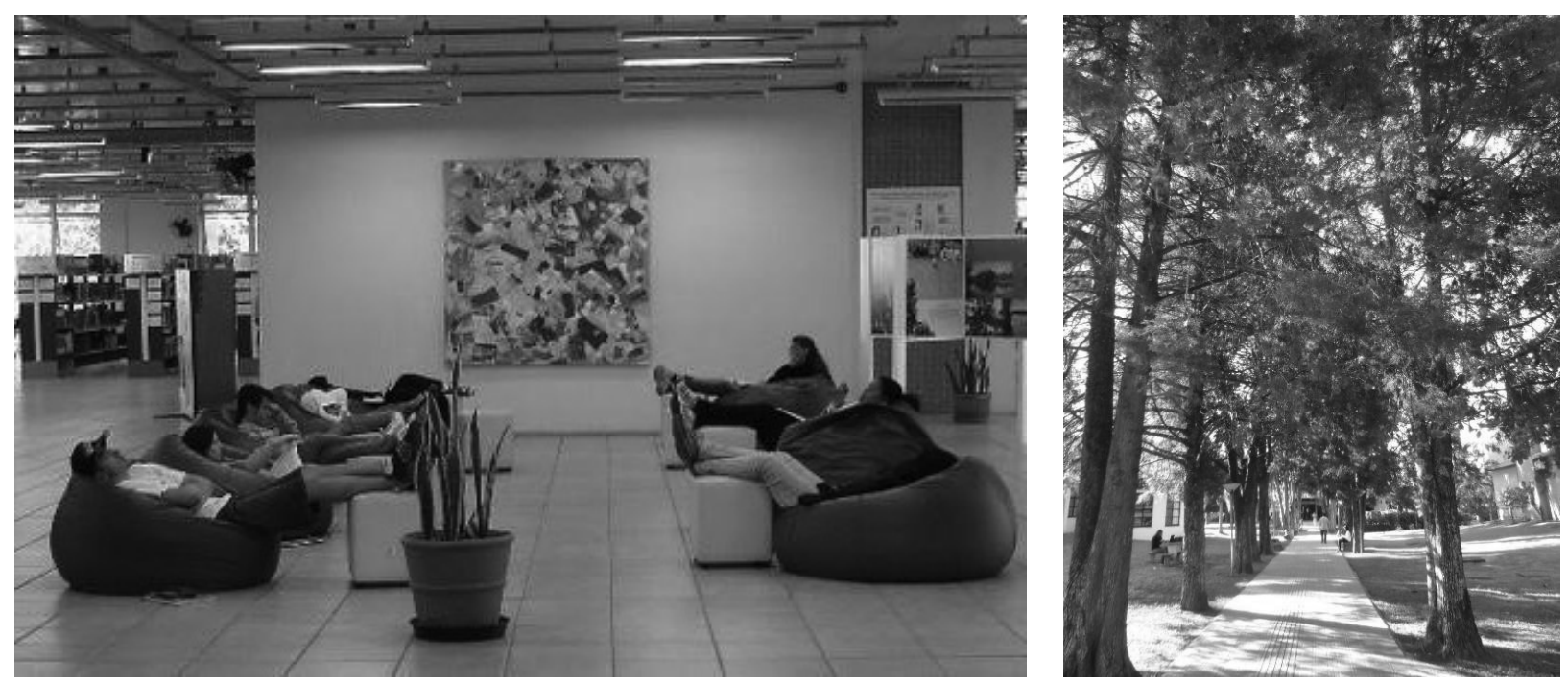

Figuras 9 e 10

A figura à esquerda corresponde à área interna da biblioteca central na qual ficam distribuídos os puffs e a figura à direita ilustra o corredor que dá acesso à biblioteca. 
tante lembrar que a capacidade restauradora dos ambientes sempre está atrelada a vivências subjetivas, contextos culturais distintos e características individuais (Berg et al., 1998).

Os espaços verdes, considerados na literatura como ambientes que suscitam maior restauro (Berg et al., 2007; Gressler, \& Günther, 2013), foram citados em ambos os campi. Contudo, no campus 2 , as interações com os espaços verdes foram predominantemente ativas, apesar do campus 1 ter área de vegetação mais extensa. Tais resultados podem ser atribuídos ao fato de que o campus 1 se configura como uma área de proteção ambiental (APA), o que impõe limitações em relação ao acesso e induz a interações mais passivas. O campus 2 sofreu maior influência humana em sua formatação, apresentando uma estrutura que sugere interações mais ativas.

Além disso, outro fator interessante observado nesse estudo foi que, em ambos os campi, o contato com espaços verdes abertos pareceram estar associados a momentos de interação ativa entre as pessoas e o ambiente, enquanto que os ambientes construídos foram utilizados para descanso individual, maior isolamento e, por vezes, interações passivas com elementos naturais.Estar sozinho ou acompanhado parece também influenciar a sensação de sentir-se ou não seguro em determinado ambiente, e, consequentemente, na possibilidade de restauro. Estudos realizados por Staats e Hartig (2004) e por Hartig e Staats (2006) concluíram que a estimulação social é mais intensa em ambientes urbanos e estar acompanhado faz o indivíduo sentir-se mais seguro. Contudo, quando o indivíduo busca isolamento para reduzir um excesso de fadiga mental, é mais provável atingir esse objetivo em ambientes com maior presença de elementos naturais.

No presente estudo, interações ativas foram mais comuns na companhia de pares e interações passivas ocorreram de maneira mais solitária. Esses aspectos, de

\section{Referências}

Alves, S. M. (2011). Ambientes restauradores. In S. Cavalcanti, \& G. A. Elali (Orgs.), Temas básicos em psicologia ambiental (pp. 44-52). Petrópolis, RJ: Vozes.

Andrade, C., Lima, M. L., Fornara, F., \& Bonaiuto, M. (2012). Users' views of hospital environmental quality: validation of the Perceived Hospital Environment Quality Indicators (PHEQIs). Jour- acordo com Kuhnen (2009), remetem ao processo de apropriação do espaço (Proshansky, Fabian, \& Kaminoff, 1983) que é dividido em duas vertentes: uma que se dirige ao outro como conquista do espaço e outra, que dirige a si mesmo na busca de satisfação de necessidades. Nesse sentido, pode-se compreender que as preferências ambientais auxiliam na distinção desses propósitos, ou seja, quando os estudantes buscavam restauro, predominavam interações passivas com os espaços verdes e quando outras demandas colocavam-se em pauta, as interações ativas eram mais recorrentes.

De acordo com Berg et al. (2003), à medida que o ambiente apresenta propriedades que possuem uma funcionalidade para o observador, esse fator colabora para ele ser escolhido para interação. Assim, apesar da existência de elementos que potencializam o restauro em determinados ambientes, a preferência ambiental passa por um processo de percepção que considera características individuais e experiências anteriores dos sujeitos com ambientes naturais e construídos (Korpela, Ylén, Tyrvainen, \& Silvennoinen, 2008). Dessa forma, a vivência restauradora se dá na relação pessoa-ambiente e é permeada por sutilezas que vão além de uma herança genética de nossos ancestrais e perpassam distintas realidades sociais.

O estudo, por seu viés qualitativo e amostra por conveniência, não permite generalizações. Os resultados restringem-se a subjetividade dos participantes e suas percepções de cada campi. Estudos posteriores podem buscar a compreensão de como os indivíduos percebem esses lugares a partir de suas referências de uso sociais e culturais, buscando delineamentos mistos e instrumentos que permitam o aprofundamento das questões discutidas. O uso da técnica da fotografia para concretização da escolha do ambiente também pode oferecer a materialização das escolhas e percepção de dificuldades inseridas no contexto, como limitações físicas e visuais.

nal of Environmental Psychology, 32(2), 97-111. doi:10.1016/j.jenvp.2011.12.001

Appleton, J. (1975). The experience of landscape. New York, NY: John Wiley.

Balling, J. D., \& Falk, J. H. (2005). Development of visual preference for natural environments. In R. G. Coss (Ed.), Environmental awareness: evolutionary, aesthetic and social perspectives (pp. 119-31). California: Kendall Hunt. 
Barcellos, V. Q. (1999). Os parques como espaços livres públicos de lazer: o caso de Brasília (Tese de doutorado). Faculdade de Arquitetura e Urbanismo, Universidade de São Paulo, São Paulo.

Berg, A. E.; Hartig, T., \& Staats H. (2007). Preference for nature in urbanized societies: stress, restoration, and the pursuit of sustainability. Journal of Social Issues, 63(1),79-96. doi:10.1111/j.1540-4560.2007.00497.x

Berg, A. E., Koole, S. L., \& Wulp, N. Y. (2003). Environmental preference and restoration: (How) are they related? Journal of Environmental Psychology, 23, 135-146. doi:10.1016/S0272-4944(02)00111-1

Berg, A. E., Vlek, C. A. J., \& Coeterier, J. F. (1998). Group differences in the aesthetic evaluation of nature development plans: a multilevel approach. Journal of Environmental Psychology, 18(2), 141-157. doi 10.1006/jevp.1998.0080

Beute, F., \& Kort, Y. A. W. (2013). Let the sun shine!: measuring explicit and implicit preference for environments differing in naturalness, weather type and brightness. Journal of Environmental Psychology, 36, 162-178. doi:10.1016/j.jenvp.2013.07.016

Brasil. (2012). Conselho Nacional de Saúde. Resolução No 466, de 12 de dezembro de 2012. [Aprovar as diretrizes e normas regulamentadoras de pesquisas envolvendo seres humanos]. Recuperado de http://conselho.saude.gov.br/resolucoes/2012/Reso466.pdf

Castelnnou, A. M. N. (2006). Parques urbanos de Curitiba: de espaços de lazer a objetos de consumo. Cadernos de Arquitetura e Urbanismo, 13(14), 53-73.

Comstock, N., Dickinson, L. M., Marshall, J. A., Soobader, M.-J., Turbin, M. S., Buchenau, M. et al. (2010). Neighborhood attachment and its correlates: exploring neighborhood conditions, collective efficacy, and gardening. Journal of Environmental Psychology, 30(4), 435-442. doi:10.1016/j.jenvp.2010.05.001

Costa, R. G. S., \& Colesanti, M. M. (2011). A contribuição da percepção ambiental nos estudos de áreas verdes. RA'EGA - O Espaço Geográfico em Análise, 22, 238-251. doi:10.5380/raega.v22i0.21774

Evans, G., \& Cohen, S. (1987). Environmental stress. In D. Stokols \& I. Altman (Eds.), Handbook of environmental psychology (pp. 571-610). New York, NY: John Wiley.

Felsten, G. (2009). Where to take a study break on the college campus: an attention restoration theory perspective. Journal of Environmental Psychology, 29(1), 160-167. doi:10.1016/j.jenvp.2008.11.006
Fischer, G. (s.d.). Psicologia social do ambiente. Lisboa: Instituto Piaget.

Galindo, M.P., Gilmartín, M.A., \&Corraliza, J. A. (2002). Em médio natural. In J. I. Aragonés, \& M. Amérigo (Coord.), Psicología ambiental (pp. 281-308). Madri: Pirámide.

García-Mira, R. (1997). La ciudad percebida:uma psicologia ambiental de los barrios de la Coruña. La Coruña: Universidade de Coruña.

Gatersleben, B., Andrews, M. (2013). When walking in nature is not restaurative: the role of prospect and refuge. Health and Place, 20, 91-101. doi:10.1016/j.healthplace.2013.01.001

Gilmartín, M. A. (2002). Ambientes escolares. In J. I. Aragonés, \& M. Amérigo (Coord.), Psicología ambiental (pp. 221-238). Madri: Pirámide.

Gressler, S. C. (2014). O descanso e a teoria dos ambientes restauradores (Tese de Doutorado). Instituto de Psicologia, Universidade de Brasília, Brasília, DF.

Gressler, S. C., \& Gunther, I. A. (2013). Ambientes restauradores: definição, histórico, abordagem e pesquisas. Estudos de Psicologia (Natal), 18(3), 487495. doi:10.1590/S1413-294X2013000300009

Hartig, T., \& Staats, H. (2003). Guest editors' introduction: restorative environments. Journal of Environmental Psychology, 23(2), 103-107. doi:10.1016/S0272-4944(02)00108-1

Hartig, T., \& Staats, H. (2006). The need for psychological restoration as a determinant of environmental preferences. Journal of Environmental Psychology, 26(3), 215-226. doi:10.1016/j.jenvp.2006.07.007

Herzog, T. R., Maguire, C. P., \& Nebel, M. B. (2003). Assessing the restorative components of environments. Journal of Environmental Psychology, 23(2), 159-170. doi:10.1016/S0272-4944(02)00113-5

Higuchi, M. I. G., \& Kuhnen, A. (2008). Percepção e representação ambiental - métodos e técnicas de investigação para a educação ambiental. In J. Q. Pinheiro, \& H. Günther (Org.), Métodos de pesquisa nos estudos pessoa-ambiente (pp. 181-215). São Paulo, SP: Casa do Psicólogo.

Honold, J., Beyer, R., Lakes, T., \& Meer, E. V. D. (2012). Multiple environmental burdens and neighborhood-related health of city residents. Journal of Environmental Psychology, 32(4), 305-317. doi:10.1016/j.jenvp.2012.05.002 
Hur, M., Nasar, J. L., \& Chun, B. (2010). Neighborhood satisfaction, physical and perceived naturalness and openness. Journal of Environmental Psychology, 30(1), 52-59. doi:10.1016/j.jenvp.2009.05.005

Kaplan, S., \& Kaplan, R. (Eds.). (1982). Humanscape: environments for people. Ann Arbor, MI: Ulrich's.

Kaplan, R., \& Kaplan, S. (1989). The experience of nature: a psychological perspective. New York, NY: Cambridge University.

Kaplan, R., \& Kaplan, S. (2011). Well-being, reasonbleness and the natural environments. Applied Psychology: Health and Well-Being, 3(3), 304-321. doi:10.1111/j.1758-0854.2011.0105.xj

Kaplan, R., Kaplan, S., \& Ryan, R. L. (1998). With people in mind: design and management of everyday nature. Washington, DC: Island.

Kaplan, S. (1995). The restorative benefits of nature: toward an integrative framework. Journal of Environmental Psychology, 15(3), 169-182. doi:10.1016/0272-4944(95)90001-2

Korpela, K., \& Hartig, T. (1996). Restorative qualities of favorite places. Journal of Environmental Psychology, 16(3), 221-233. doi:10.1006/jevp.1996.0018

Korpela, K. M., Ylén, M., Tyrvainen, L., \& Silvennoinen, H. (2008). Determinants of restorative experiences in everyday favorite places. Health and Place, 14(4), 636-652. doi:10.1016/j.healthplace.2007.10.008

Kuhnen, A. (2009). Interações humano-ambientais e comportamentos socioespaciais. In A. Kuhnen, R. M. Cruz, \& Takase, E. (Org.), Interações pessoa-ambiente e saúde (pp.15-35). São Paulo, SP: Casa do Psicólogo.

Kuhnen, A. (2012). Percepções da comunidade universitária sobre o Bosque do Planetário - campus universitário da UFSC. Revista de Ciências Humanas, 46(2), 383-397. Recuperado de https://periodicos.ufsc.br/index.php/revistacfh/article/view/ 2178-4582.2012v46n2p383/24190

Kuhnen, A., \& Higuchi, M. I. G. (2011). Percepção ambiental. In S. Cavalcante, \& G. A. Elali (Org.), Temas básicos em psicologia ambiental (pp. 250-266). São Paulo, SP: Vozes.

Lázaro, V., \& Cabrerizo, A. (2002). Cualidade de vida em el entorno del campus de la Universidade de La Rioja. In R. García-Mira (Ed.), Psicologia y medio ambiente: aspectos psicosociales, educativos y metodológicos. La Corunã: A Coruña.
Manaus. (2012). Decreto No 1.503, de 27 de março de 2012. Cria a Área de Proteção Ambiental UFAM, INPA, ULBRA, ELISA MIRANDA, LAGOA DO JAPIIM E ACARIQUARA e dá outras providências. Diário Oficial do Município de Manaus, 27 de março.

McFarland, A. L., Waliczek, T. M., \& Zajicek, J. M. (2010). Graduate student use of campus green spaces and the impact on their perceptions of quality of life. HortTechnology, 20(1), 186-192. Recuperado de http://horttech.ashspublications.org/content/20/1/186.full

McFarland, A. L., Waliczek, T. M., \& Zajicek, J. M. (2008). The relationship between student use of campus green spaces and perceptions of quality of life. HortTechnology, 18(2), 232-238. Recuperado de http://horttech.ashspublications.org/content/18/2/232.full

Martínez-Soto, J., \& López-Lena, M. M. (2010). Percepción de cualidades restauradoras y preferencia ambiental. Revista Mexicana de Psicología, 27(2), 183-190. Recuperado de http://www.redalyc.org/ pdf/2430/243016324007.pdf

Polli, G. M., \& Kuhnen, A. (2011). Possibilidades de uso da teoria das representações sociais para os estudos pessoa-ambiente. Estudos de Psicologia (Natal), 16(1),57-64.doi:10.1590/S1413-294X2011000100008

Proshansky, H. M., Fabian, A. K., \& Kaminoff, R. (1983). Place identity: physical world socialization of the self. Journal of Environmental Psychology, 3(1), 57-83. doi:10.1016/S0272-4944(83)80021-8

Raanaas, R. K., Horgen, K., Rich, D., Sjøstrøm, G., \& Patil, G. (2011). Benefits of indoor plants on attention capacity in an office setting. Journal of Environmental Psychology, 31(1), 99-105. doi:10.1016/j.jenvp.2010.11.005

Scopelliti, M., \& Giuliani, M. V. (2004). Choosing restorative environments across the lifespan: a matter of place experience. Journal of Environmental Psychology, 24, 423-427. doi:10.1016/j.jenvp.2004.11.002

Speake, J., Edmondson, S., \& Nawaz, H. (2013). Everyday encounters with nature: students' perceptions and use of university green spaces. Human Geographies - Journal of Studies and Research in Human Geography, 7(1), 21-31.

Staats, H., \& Hartig, T. (2004). Alone or with a friend: A social context for psychological restoration and environmental preferences. Journal of Environmental Psychology, 24, 199-211. DOI: 10.1016/j.jenvp.2003.12.005 
Steuer, I. R. W., Araújo, G.V.R., Oliveira, B. M. C., Silva, T. E. P., \& El-Deir, S. G. (2012). Gerenciamento de áreas verdes na Universidade Federal Rural de Pernambuco (UFRPE) para recomposição florestal. In: Anais do III Congresso Brasileiro de Gestão Ambiental (pp. 1-9). Goiânica, GO. Disponível em http://www. ibeas.org.br/congresso/Trabalhos2012/VI-047.pdf

Ulrich, R. S. (1983). Aesthetic and affective response to natural environment. In I. Altman, \& J. F. Wohlwill (Ed.), Behaviour and the natural environment (pp. 85-125). New York, NY: Plenum.

Ulrich, R. S. (1977). Visual landscape preference: a model and application. Man-Environment Systems, 7(5), 279-293.

Ulrich, R. S. (1979). Visual landscapes and psychological well-being. Landscape Research, 4(1), 17-23. doi:10.1080/01426397908705892

Ulrich, R. S., Simons, R. F., Losito, B. D., Fiorito, E., Miles, M. A., \& Zelson, M. (1991). Stress recovery during exposure to natural and urban environments. Journal of Environmental Psychology, 11(3), 201-230. doi:10.1016/S0272-4944(05)80184-7

Varney, H. et al. (2014). Losing, and finding, spaces to learn in the university. Emotion, Space and Society, 11,36-42. doi:10.1016/j.emospa.2013.03.003

Dayse da Silva Albuquerque

Mestranda do Programa de Pós-Graduação em Psicologia da Universidade Federal de Santa Catarina, Florianópolis - SC. Brasil.

E-mail: albuquerquepsi@hotmail.com
Dnyelle Souza Silva

Mestre em Ciências pela Faculdade de Medicina da Universidade de São Paulo, São Paulo - SP. Brasil.

E-mail: dnyelle.silva@yahoo.com

Ariane Kuhnen

Doutora em Ciências Humanas. Docente

da Universidade Federal de Santa Catarina,

Florianópolis - SC. Brasil.

E-mail: ariane.kuhnen@ufsc.br

Endereço para envio de correspondência:

LAPAM - Laboratório de Psicologia Ambiental

lapam.cfh.ufsc

Departamento de Psicologia

Programa de Pós-graduação em Psicologia.

UFSC - Universidade Federal de Santa Catarina

Recebido 22/09/2015

Reformulação 09/08/2016

Aprovado 04/11/2016

Received 09/22/2015

Reformulated $08 / 09 / 2016$

Approved 11/04/2016

Recibido 22/09/2015

Reformulado 09/08/2016

Aceptado 04/11/2016

Como citar: Albuquerque, D. S., Silva, D. S., \& Kuhnen, A. (2016). Preferências ambientais e possibilidades de restauro psicológico em campi universitários. Psicologia: Ciência e Profissão, 36(4): 893-906.

doi:10.1590/1982-3703002972015

How to cite: Albuquerque, D. S., Silva, D. S., \& Kuhnen, A. (2016). Environmental preferences and psychological restoration possibilities in universities campuses. Psicologia: Ciência e Profissão, 36(4): 893-906. doi:10.1590/1982-3703002972015

Cómo citar: Albuquerque, D. S., Silva, D. S., \& Kuhnen, A. (2016). Preferencias ambientales y posibilidad de restauración psicológica en campus universitarios. Psicologia: Ciência e Profissão, 36(4): 893-906. doi:10.1590/1982-3703002972015 